\title{
Alteration of regression of cholesterol accumulation in rats by dietary pectin
}

\author{
BY JAMES N. THOMAS*, MICHAEL J. KELLEY† AND JON A. STORY \\ Department of Foods and Nutrition, Purdue University, West Lafayette, IN 47907, USA
}

(Received 4 March 1983 - Accepted 11 November 1983)

\begin{abstract}
1. Male, Wistar rats (50-74 g) were given a semi-purified diet containing cholesterol $(10 \mathrm{~g} / \mathrm{kg} \mathrm{diet})$ for 4 weeks, groups of control and experimental animals killed, and the remainder of the cholesterol-fed animals given either a semi-purified cholesterol-free diet without a fibre source or a similar diet with pectin $(50 \mathrm{~g} / \mathrm{kg}$ diet $)$ for 8 weeks. Animals were killed at 2 -week intervals and serum and liver cholesterol and triglycerides, faecal neutral steroids and acidic steroids measured.

2. Animals given pectin had significantly lower serum cholesterol levels than animals given the basal diet after 4 and 6 weeks.

3. Both experimental groups efficiently decreased their liver cholesterol levels during regression.

4. Bile acid excretion was elevated in both groups, especially in rats receiving pectin, but neutral steroid excretion was unchanged.

5. The increase in bile acid excretion was primarily in the form of chenodeoxycholic acid and its metabolites.

6. This increased bile acid excretion is postulated to result from stimulation of the normal mechanism for increased steroid excretion in the rat, i.e. a change in the value of cholic: chenodeoxycholic acid or from a mechanism not yet elucidated.
\end{abstract}

Components of dietary fibre have different capacities for reducing cholesterol concentrations (serum or liver), pectin being one of the more consistent in accomplishing this reduction in man (Jenkins et al. 1975; Kay \& Truswell, 1977; Miettinen \& Tarpila, 1977) and in rats (Wells \& Ershoff, 1961; Palmer \& Dixon, 1966; Karvinen \& Miettinen, 1968). The mechanism by which pectin lowers cholesterol levels is still under debate. Increased faecal bile acid excretion has been reported in response to pectin in humans (Kay \& Truswell, 1977; Miettinen \& Tarpila, 1977) and in rats (Reddy et al. 1980). In rats, cholesterol absorption has also been reported to be reduced by dietary pectin in comparison with cellulose when measured as disappearance of radioactive dietary cholesterol (Chang \& Johnson, 1980), while lymphatic appearance of cholesterol has been reported to be higher when pectin is compared with cellulose, but lower when compared with a commercial ration (Vahouny et al. 1980). The experiments reported here utilize a progression-regression design in which liver cholesterol levels of rats were increased by feeding cholesterolcontaining diets and the rate of regression of this accumulated cholesterol was examined in an effort to define better the cholesterol-lowering properties of pectin.

\section{MATERIALS AND METHODS}

Sixty-one male, weanling, Wistar rats (Harlan Industries, Inc., Indianapolis, IN, USA) weighing 50-74 $\mathrm{g}$ were given either a basal (B) or a basal plus $10 \mathrm{~g}$ cholesterol $/ \mathrm{kg}$ (BC) semi-purified diet for 4 weeks (Table 1). Rats were housed in individual cages and given food and water ad lib. Five of the BC-fed animals and six of the B-fed animals were killed by exsanguination after 4 weeks to establish base-line levels of lipid accumulation. The remaining rats which had received the $\mathrm{BC}$ diet were divided into two groups which were

* Present addresses: Department of Nutrition and Food Science, Massachusetts Institute of Technology, Cambridge, MA, USA. $\dagger$ Department of Nutrition, Harvard School of Public Health, Boston, MA, USA.

$\ddagger$ For reprints. 
Table 1. Composition $(\mathrm{g} / \mathrm{kg})$ of diets

\begin{tabular}{|c|c|c|c|}
\hline \multirow[b]{2}{*}{ Component } & \multicolumn{3}{|c|}{ Diet } \\
\hline & $\mathrm{B} / \mathrm{BR}$ & BC & $\mathrm{BP}$ \\
\hline Sucrose* & 600 & 590 & 550 \\
\hline Casein (vitamin free) $\dagger$ & 250 & 250 & 250 \\
\hline Maize oil $\ddagger$ & 100 & 100 & 100 \\
\hline Salt mix (AIN)§ & 40 & 40 & 40 \\
\hline Vitamin fortification (AIN) $\dagger$ & 10 & 10 & 10 \\
\hline Cholesterol (USP) $\dagger$ & 0 & 10 & 0 \\
\hline Pectin (citrus, methoxy content $7.5 \%)$ & 0 & 0 & 50 \\
\hline
\end{tabular}

* The South Corporation, Houma, LA, USA.

$\ddagger$ Best Foods, Englewood Cliffs, NJ, USA. $\dagger$ Bioserve, Frenchtown, NJ, USA.

$\S$ Sigma, St Louis, MO, USA.

given either the basal (designated BR) or basal plus $50 \mathrm{~g}$ pectin $/ \mathrm{kg}$ (BP) diet (Táble 1). Six rats given the BP diet and five rats given the BR diet were killed at 2-week intervals for 8 weeks, and serum and liver samples frozen at $-20^{\circ}$ for subsequent analysis. A control group, given diet B for the entire experiment, was killed at week 12. Serum and liver cholesterol levels were determined by the method of Rudel \& Morris (1973) and serum triglycerides by a combination of the methods of Van Handel \& Zilversmit (1957) and Ryan \& Rasho (1967).

Forty-eight hour faecal samples were collected, pooled by dietary group, and freeze-dried in preparation for bile acid and neutral steroid determination (Grundy et al. 1965; Brydon et al. 1979). Samples were ground to a fine powder and $1-\mathrm{g}$ portions were digested with acetic acid at $110^{\circ}$ for $1.5 \mathrm{~h}$ after the addition of internal standards (23-nordeoxycholic acid for bile acids and 5- $\alpha$-cholestane for neutral steroids, $0.5 \mathrm{mg}$ each). After cooling, toluene was added and a sample removed, dried and subjected to enzymic hydrolysis of the bile acid conjugates with cholyglycine hydrolase (EC 3.5.1 .24; Sigma, St Louis, MO, USA). Neutral steroids were extracted with petroleum ether $(4 \times 10 \mathrm{ml})$, after addition of $7.5 \mathrm{M}-\mathrm{NaOH}$, to $\mathrm{pH} 10$ and analysed as their trimethylsilyl ethers by gas-liquid chromatography (Hewlett-Packard 5710A, Avondale, PA, USA) using 3\% OV-17 on 100/120 Supelcoport (Supelco, Bellefonte, PA, USA). The residue was then acidified to $\mathrm{pH} 1$ with hydrochloric acid and bile acids extracted with diethyl ether $(3 \times 25 \mathrm{ml})$ and ethyl acetate $(2 \times 25 \mathrm{ml})$. The combined extracts were dried and methylated with $0.2 \mathrm{ml}$ concentrated $\mathrm{HCl}$ and $2.0 \mathrm{ml}$ dimethoxypropane. Methylated bile acids were separated by thin-layer chromatography on $500 \mu \mathrm{m}$ silica gel G (Analtech Inc., Newark, DE, USA) and developed in isooctane - isopropanol - acetic acid $(60: 20: 0 \cdot 5$, by vol.) with appropriate standards (Supelco). Iodine vapours were used to visualize the bile acids, and the area between and including methylated cholic and lithocholic standards was removed, the bile acids eluted from the silica gel and acetylated with a cooled reagent consisting of $14 \mathrm{ml}$ acetic acid (glacial), $10 \mathrm{ml}$ acetic anhydride and $50 \mu \mathrm{l}$ perchloric acid. The esterified bile acids were analysed by gas-liquid chromatography using a column containing $3 \% \mathrm{SP}-2100$ on $100 / 120$ mesh Supelcoport (Supelco). Bile acids and neutral steroids were identified by comparison of relative retention times with standards and measured using the internal standard corrected for differences in detector response.

RESULTS

As can be seen in Table 2, no significant difference in serum cholesterol resulted from the 4-week cholesterol feeding period. This lack of change in serum cholesterol in response to 
Table 2. Effect of pectin on serum $(S)$ and liver $(L)$ cholesterol $(C H O L)$ and triglycerides $(T G)$

(Mean values with standard errors of the mean)

\begin{tabular}{|c|c|c|c|c|c|c|c|c|c|}
\hline \multirow[b]{2}{*}{ Week } & \multirow[b]{2}{*}{ Diet } & \multicolumn{2}{|c|}{$\begin{array}{c}\mathrm{SCHOl} \\
(\mathrm{mmol} / \mathrm{l})\end{array}$} & \multicolumn{2}{|c|}{$\begin{array}{c}\text { LCHOL } \\
(\mu \mathrm{mol} / \mathrm{g})\end{array}$} & \multicolumn{2}{|c|}{$\begin{array}{c}\text { STG } \\
(\mathrm{mg} / \mathrm{l})\end{array}$} & \multicolumn{2}{|c|}{$\begin{array}{l}\text { LTG } \\
(\mathrm{mg} / \mathrm{g})\end{array}$} \\
\hline & & Mean & SEM & Mean & SEM & Mean & SEM & Mean & SEM \\
\hline 4 & $\begin{array}{l}\text { B } \\
\text { BC }\end{array}$ & $\begin{array}{l}1.39 \\
1.22\end{array}$ & $\begin{array}{l}0.07 \\
0 \cdot 14\end{array}$ & $\begin{array}{r}9 \cdot 7^{*} \\
44.5 \dagger\end{array}$ & $\begin{array}{l}0.8 \\
4.9\end{array}$ & $\begin{array}{l}254 \\
222\end{array}$ & $\begin{array}{l}40 \\
29\end{array}$ & $\begin{array}{l}17 \cdot 1 \\
39 \cdot 0\end{array}$ & $\begin{array}{r}9 \cdot 0 \\
16 \cdot 1\end{array}$ \\
\hline 6 & $\begin{array}{l}\text { BR } \\
\text { BP }\end{array}$ & $\begin{array}{l}1.52 \\
1.24\end{array}$ & $\begin{array}{l}0.19 \\
0.12\end{array}$ & $\begin{array}{l}13 \cdot 7^{*} \\
11.6^{*}\end{array}$ & $\begin{array}{l}2.9 \\
0.5\end{array}$ & $\begin{array}{l}316 \\
278\end{array}$ & $\begin{array}{l}21 \\
31\end{array}$ & $\begin{array}{l}17 \cdot 2 \\
16 \cdot 1\end{array}$ & $\begin{array}{l}4.8 \\
1.6\end{array}$ \\
\hline 8 & $\begin{array}{l}\text { BR } \\
\text { BP }\end{array}$ & $\begin{array}{l}1 \cdot 69 * \S \\
1 \cdot 25 \ddagger\end{array}$ & $\begin{array}{l}0.11 \\
0.11\end{array}$ & $\begin{array}{l}9 \cdot 1^{*} \\
11 \cdot 4^{*}\end{array}$ & $\begin{array}{l}0.5 \\
1.0\end{array}$ & $\begin{array}{l}313 \\
267\end{array}$ & $\begin{array}{l}57 \\
33\end{array}$ & $\begin{array}{r}7 \cdot 4 \\
14 \cdot 4\end{array}$ & $\begin{array}{l}0.9 \\
2.7\end{array}$ \\
\hline $\begin{array}{l}10 \\
12\end{array}$ & $\begin{array}{l}\text { BR } \\
\text { BP } \\
\text { BR } \\
\text { BP } \\
\text { B }\end{array}$ & $\begin{array}{l}1.58 \mathrm{~m} \\
1.10 \ddagger \\
1.89 \\
1.09 \\
1.47\end{array}$ & $\begin{array}{l}0.05 \\
0.09 \\
0.20 \\
0.08 \\
0.18\end{array}$ & $\begin{array}{r}9 \cdot 1^{*} \\
11 \cdot 1^{*} \\
10 \cdot 9^{*} \\
9 \cdot 8^{*} \\
11 \cdot 6^{*}\end{array}$ & $\begin{array}{l}0.5 \\
0.8 \\
0.8 \\
0.8 \\
1.0\end{array}$ & $\begin{array}{l}332 \\
224 \\
329 \\
289 \\
369\end{array}$ & $\begin{array}{l}76 \\
27 \\
45 \\
31 \\
41\end{array}$ & $\begin{array}{l}13.8 \\
18.9 \\
30.4 \\
18.9 \\
19.8\end{array}$ & $\begin{array}{r}2.8 \\
4.5 \\
14.5 \\
3.8 \\
5.0\end{array}$ \\
\hline
\end{tabular}

For details of diets, see Table 1.

- Significantly different than for BC at week $4(P<0.05)$.

$\dagger$ Significantly different than for B at week $4(P<0.05)$.

$\ddagger$ Significantly different than for BR, within week $(P<0.05)$.

$\S$ Significantly different than for BP, within week $(P<0 \cdot 05)$.

dietary cholesterol in the rat has been observed previously (Story et al. 1981 a,b). Serum cholesterol levels increased when cholesterol was removed from the diet (BR) and were significantly $(P<0.05)$ higher than the base-line level after 8 and 10 weeks but at no time significantly higher than in the group which was never given cholesterol (B). Pectin appears to have prevented this increase in serum cholesterol in response to removal of dietary cholesterol as demonstrated by the relatively constant serum cholesterol levels of animals given diet BP in comparison with those given diet BR.

Conversely, liver cholesterol levels were significantly $(P<0.05)$ increased by cholesterol feeding, animals given cholesterol having concentrations of liver cholesterol 4.7 times higher than those given cholesterol-free diets. Removal of cholesterol from the diet for 2 weeks resulted in a return to levels close to those found in animals given diet $\mathrm{B}$, for groups given either BP or BR. No statistically significant differences between groups given diets BR or $B P$ were observed at any of the time points during regression. Serum and liver triglycerides were not significantly altered by any of the dietary treatments except for an increase in liver triglyceride level (2-3-fold) in cholesterol-fed rats at the base-line time point (BC).

Neutral steroid excretion in faeces (Table 3) was extremely high during cholesterol feeding but dropped dramatically when cholesterol was removed from the diet (BC $v$. BR and BP). During regression, basal- and pectin-fed animals excreted similar amounts of neutral steroid, both being consistently, but not significantly lower than the group never given cholesterol (B).

Faecal bile acid excretion (Table 4) increased in response to cholesterol feeding. When cholesterol was removed from the diet (BR), bile acid excretion declined slightly after 1 week and returned to levels similar to basal-fed animals by week 6 . When pectin was added (BP), bile acid excretion increased dramatically and remained higher than in group B or BR until week 7 when it decreased to a level slightly higher than the other groups. Concentration of bile acids in faeces was higher in pectin-fed animals at each time point except at 7 weeks. 
Table 3. Effect of pectin on faecal neutral steroid excretion

(Values are means of three replicates of pooled faecal samples)

\begin{tabular}{|c|c|c|c|c|c|c|c|c|c|}
\hline \multirow[b]{2}{*}{ Diet } & \multicolumn{3}{|c|}{ Progression (weeks) } & \multicolumn{6}{|c|}{ Regression (weeks) } \\
\hline & 2 & 3 & 4 & 5 & 6 & 7 & 8 & 9 & 10 \\
\hline \multicolumn{10}{|c|}{ Concentration ( $\mathrm{mg} / \mathrm{g}$ faeces) } \\
\hline BC & $120 \cdot 0$ & $100 \cdot 4$ & $106 \cdot 8$ & - & -. & - & $\ldots$ & $\ldots$ & - \\
\hline B & $14 \cdot 0$ & $27 \cdot 2$ & $20 \cdot 3$ & $10 \cdot 1$ & - & 8.9 & $13 \cdot 8$ & 9.9 & 14.9 \\
\hline BR & - & - & - & $5 \cdot 8$ & 6.5 & 7.0 & $9 \cdot 7$ & 5.6 & 8.4 \\
\hline BP & - & 一 & - & $5 \cdot 5$ & $5 \cdot 4$ & $4 \cdot 6$ & $4 \cdot 4$ & 6.5 & 6.0 \\
\hline \multicolumn{10}{|c|}{ Excretion (mg/d) } \\
\hline BC & $141 \cdot 6$ & 123.5 & 133.5 & - & - & - & - & - & - \\
\hline B & $15 \cdot 4$ & $29 \cdot 1$ & $22 \cdot 4$ & 11.8 & - & $8 \cdot 3$ & $20 \cdot 0$ & $15 \cdot 5$ & $30 \cdot 6$ \\
\hline BR & - & - & - & 6.7 & $5 \cdot 6$ & $7 \cdot 1$ & $17 \cdot 3$ & $12 \cdot 0$ & $24 \cdot 4$ \\
\hline BP & - & - & - & $8 \cdot 0$ & $10 \cdot 9$ & $8 \cdot 1$ & $10 \cdot 8$ & $16 \cdot 7$ & 22.9 \\
\hline
\end{tabular}

For details of diets, see Table 1.

Table 4. Effect of pectin on faecal bile acid excretion

(Values are means of three replicates of pooled faecal samples)

\begin{tabular}{|c|c|c|c|c|c|c|c|c|c|}
\hline \multirow[b]{2}{*}{ Diet } & \multicolumn{3}{|c|}{ Progression (weeks) } & \multicolumn{6}{|c|}{ Regression (weeks) } \\
\hline & 2 & 3 & 4 & 5 & 6 & 7 & 8 & 9 & 10 \\
\hline \multicolumn{10}{|c|}{ Concentration $(\mathrm{mg} / \mathrm{g})$} \\
\hline $\mathrm{BC}$ & $2 \cdot 33$ & $5 \cdot 76$ & 10.46 & - & - & - & - & - & - \\
\hline $\mathbf{B}$ & 2.59 & $3 \cdot 40$ & $3 \cdot 80$ & 4.81 & $5 \cdot 33$ & $7 \cdot 69$ & $7 \cdot 01$ & $4 \cdot 24$ & $6 \cdot 12$ \\
\hline BR & - & - & - & $10 \cdot 58$ & $10 \cdot 37$ & $7 \cdot 85$ & $5 \cdot 43$ & $4 \cdot 31$ & 1.79 \\
\hline BP & - & - & - & $11 \cdot 69$ & 13.95 & 6.40 & $6 \cdot 85$ & 5.61 & 3.35 \\
\hline \multicolumn{10}{|c|}{ Excretion (mg/d) } \\
\hline $\mathbf{B C}$ & 2.75 & $7 \cdot 08$ & $13 \cdot 08$ & - & - & - & - & - & - \\
\hline B & 3.95 & $3 \cdot 64$ & $4 \cdot 18$ & 5.63 & $8 \cdot 21$ & $7 \cdot 23$ & $10 \cdot 52$ & $6 \cdot 66$ & $12 \cdot 52$ \\
\hline BR & - & - & - & $12 \cdot 17$ & 9.02 & 8.01 & $9 \cdot 71$ & $9 \cdot 26$ & $5 \cdot 19$ \\
\hline $\mathbf{B P}$ & - & - & - & $17 \cdot 07$ & 28.04 & $11 \cdot 20$ & $16 \cdot 78$ & 14.42 & $12 \cdot 82$ \\
\hline
\end{tabular}

For details of diets, see Table 1.

During cholesterol feeding, faecal excretion of chenodeoxycholic acid and its metabolites (lithocholic, hyodeoxycholic, $\alpha$-, $\beta$ - and $\omega$-muricholic acids) increased dramatically, as a percentage of total bile acids excreted, to $88.7 \%$ in comparison with $70.5 \%$ in basal-fed rats at week 4 (Figs 1 and 2). At 6 weeks, pectin-fed animals (BP) were excreting a much higher percentage of bile acids as chenodeoxycholic acid derivatives $(87.0 \%$ ) than animals given the fibre-free diet (BR; 78.3\%), but levels for both groups remained elevated. By week 7, levels for both groups had returned to a value similar to that observed in animals never given cholesterol (BP, $65 \cdot 1 \%$; BR, 68.2\%; B, 64.7\%).

\section{DISCUSSION}

The higher serum cholesterol level in rats after removal of dietary cholesterol and the fact that no pectin was present may result from a loss of the constant dietary stimulus regulating serum cholesterol level. Pectin, by increasing the flux of steroid through bile and out of the body, prevents this rebound. Others have observed similar increases in serum and liver 


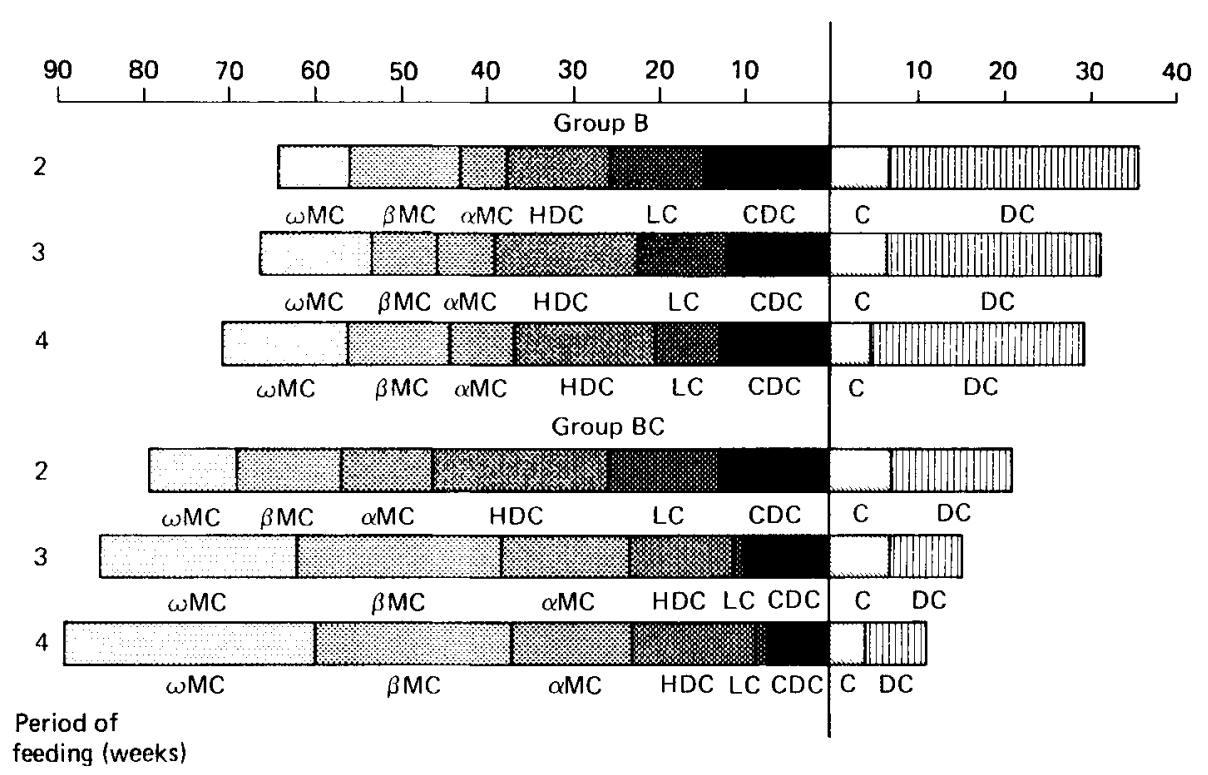

Fig. 1. Spectrum of bile acids excreted by groups given $B$ and BC diets for 2, 3 and 4 weeks as indicated. CDC, chenodeoxycholic acid; LC, lithocholic acid; HDC, hyodeoxycholic acid; MC, muricholic acid; C, cholic acid; DC, deoxycholic acid. For details of diets, see Table 1.

cholesterol in response to dietary cholesterol using this semi-purified diet, and have reported an ability of pectin to reduce this accumulation (Wells \& Ershoff, 1961; Story et al. $1981 a, b$ ).

The increase in the relative amount of chenodeoxycholic acid metabolites, excreted in response to dietary cholesterol, confirms the work of Gustafsson et al. $(1975,1977)$ who made similar observations in both conventional and germ-free rats. Although dietary cholesterol does not cause an increase in total bile acid secretion in humans (Spritz et al. 1965; Wilson \& Lindsey, 1965), the relative amount of chenodeoxycholic acid increases in relation to cholic acid in bile in response to cholesterol feeding. In rats, chenodeoxycholic acid and other dihydroxy bile acids are less efficiently reabsorbed from the small intestine and, possibly as a result of this difference, generally have a shorter half-life than trihydroxy bile acids (Beher $e t$ al. 1967). Adsorption of dihydroxy bile acids by dietary fibre is greater than trihydroxy bile acids in vitro (Eastwood \& Hamilton, 1968; Birkner \& Kern, 1974; Kay et al. 1979) and chenodeoxycholic acid is preferentially bound to the particulate matter of stools from patients given dietary fibre (Kern et al. 1978). This increased proportion of chenodeoxycholic acid in bile may result in increased excretion through decreased reabsorption and, when dietary fibre is present, through adsorption on dietary fibre. In addition, feeding chenodeoxycholic acid to rats decreases cholesterol absorption and inhibits cholesterol synthesis (Shefer et al. 1973; Cohen et al. 1977; Uchida et al. 1980). In the present study, after liver cholesterol returned to near base-line levels and total bile acid excretion declined, the amount of chenodeoxycholic acid also returned to levels similar to those of rats which had not been given cholesterol. This indicates the ability of the rat to increase synthesis of chenodeoxycholic acid and its metabolites when faced with excess cholesterol (dietary or stored), thus increasing excretion until cholesterol levels return to normal.

The increased excretion of chenodeoxycholic metabolites by pectin-fed animals, in 


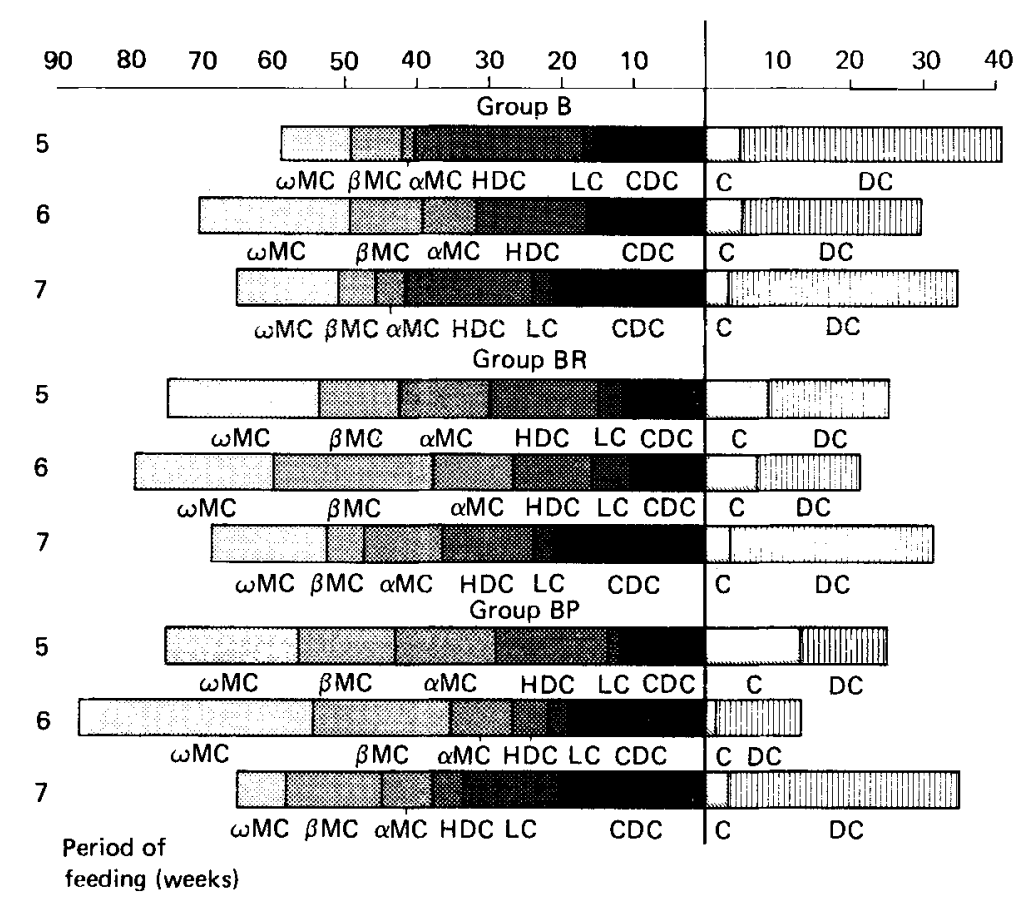

Fig. 2. Spectrum of bile acids excreted by groups given B, BR and BP diets during regression of cholesterol accumulation (indicated as weeks 5, 6 and 7). CDC, chenodeoxycholic acid; LC, lithocholic acid; HDC, hyodeoxycholic acid; MC muricholic acid; C, cholic acid; DC, deoxycholic acid. For details of diets, see Table 1.

comparison with animals given fibre-free diets, indicates that pectin may enhance the ability of the rat to excrete accumulated cholesterol by increased synthesis of the bile acids which are preferentially excreted, i.e. chenodeoxycholic acid and its metabolites. This change may result from adsorption of these bile acids by pectin resulting in their appearance in a greater proportion in faeces. Little evidence is available concerning the adsorption of bile acids by pectin. Modification of the activities of the enzymes involved in determining the spectrum of bile acids synthesized would also explain the observed changes. Recent evidence indicates that pectin and other unavailable polysaccharides are broken down by intestinal bacteria in humans and that the products of this activity are absorbed (Cummings et al. 1979). Volatile fatty acids generated in this manner may be influencing the activities of these and other enzymes of lipid metabolism.

The results of the present study suggest that pectin may alter bile acid excretion by altering the identity of bile acids synthesized to favour those which promote excretion as a result of their preferential adsorption or decreased reabsorption. We are currently examining the mechanisms for these changes in the bile acid spectrum with pectin and other dietary fibre components and foods. Evaluation of these changes in bile acid pool size and excretion levels in the light of their relation to human diseases other than coronary heart disease (e.g. gallstones, colon cancer) would seem advisable before dietary recommendations are made.

The authors acknowledge the kind gift of $\alpha$ - and $\beta$-muricholic acids from Dr W. H. Elliott, St Louis University. These results were presented, in part, at the 64th Annual Meeting of 
the Federation of American Societies for Experimental Biology, Anaheim, CA, in April 1980 (Thomas et al. 1980). This work was supported, in part, by the Indiana Agricultural Experiment Station (paper no. 8712), the Northeast Indiana Chapter of the Indiana Affiliate of the American Heart Association and the Showalter Trust.

\section{REFERENCES}

Beher, W. T., Beher, M. E. \& Rao, B. (1967). Life Sciences 6, 863-866.

Birkner, H. J. \& Kern, F. Jr (1974). Gastroenterology 67, 237-244.

Brydon, W. G., Tadesse, K., Smith, D. M. \& Eastwood, M. A. (1979). Journal of Chromatography 172, $450-452$.

Chang, M. L. W. \& Johnson, M. A. (1980). Nutrition Reports International 22, 91-99.

Cohen, B. I., Raicht, R. R. \& Mosbach, E. H. (1977). Journal of Lipid Research 18, 223-231.

Cummings, J. H., Southgate, D. A. T., Branch, W. J. \& Wiggins, H. S. (1979). British Journal of Nutrition 41, 477-485.

Eastwood, M. A. \& Hamilton, D. (1968). Biochimica et Biophysica Acta 152, 165-173.

Grundy, S. M., Ahrens, E. H. Jr \& Miettinen, T. A. (1965). Journal of Lipid Research 6, 397-409.

Gustafsson, B. E., Angelin, B., Einarsson, K. \& Gustafsson, J.-A. (1977). Journal of Lipid Research 18, 717-721. Gustafsson, B. E., Einarsson, K. \& Gustafsson, J.-A. (1975). Journal of Biological Chemistry 250, 8496-8502.

Jenkins, D. J. A., Newton, C., Leeds, A. R. \& Cummings, J. H. (1975). Lancet i, 116-117.

Karvinen, E. \& Miettinen, M. (1968). Acta Physiologica Scandinavica 72, 62-64.

Kay, R. M., Strasberg, S. M., Pertunka, C. N. \& Wayman, M. (1979). Dietary Fibers: Chemistry and Nutrition, pp. 57-65 [G. E. Inglett and S. I. Falkehag, editors]. New York: Academic Press.

Kay, R. M. \& Truswell, S. W. (1977). American Journal of Clinical Nutrition 30, 171-175.

Kern, J. Jr, Birkner, H. J. \& Ostrower, V. S. (1978). American Journal of Clinical Nutrition 31, S175-S179.

Miettinen, T. S. \& Tarpila, S. (1977). Clinica Chimica Acta 79, 471-477.

Palmer, G. H. \& Dixon, D. G. (1966). American Journal of Clinical Nutrition 18, 437-442.

Reddy, B. S., Watamabe, K. \& Sheinfil, A. (1980). Journal of Nutrition 110, 1247-1254.

Rudel, L. L. \& Morris, M. D. (1973). Journal of Lipid Research 14, 364-366.

Ryan, W. G. \& Rasho, O. M. (1967). Clinical Chemistry 13, 769-772.

Shefer, S., Hauser, D., Lapar, V. \& Mosbach, E. H. (1973). Journal of Lipid Research 14, 573-580.

Spritz, N., Ahrens, E. H. Jr \& Grundy, S. (1965). Journal of Clinical Investigation 44, 1482-1493.

Story, J. A., Baldino, A., Czarnecki, S. K. \& Kritchevsky, D. (1981a). Nutrition Reports International 24, $1213-1219$.

Story, J. A., Czarnecki, S. K., Tepper, S. A. \& Kritchevsky, D. (1981 b). Nutrtion Reports International 24, $465-470$.

Thomas, J. N., Kelley, M. J. \& Story, J. A. (1980). Federation Proceedings of the American Societies for Experimental Biology 39, 784.

Uchida, K., Nomura, Y. \& Takeuchi, N. (1980). Journal of Biochemistry 87, 187-194.

Vahouny, G. V., Roy, T., Gallo, L. L., Story, J. A., Kritchevsky, D. \& Cassidy, M. M. (1980). American Journal of Clinical Nutrition 33, 2182-2191.

Van Handel, E. V. \& Zilversmit, D. B. (1957). Journal of Laboratory and Clinical Medicine 50, $152-157$.

Wells, A. F. \& Ershoff, B. H. (1961). Journal of Nutrition 74, 87-92.

Wilson, J. D. \& Lindsey, C. A. Jr (1965). Journal of Clinical Investigation 44, 1805-1814. 